UNIVERSIDADE DE BRASÍLIA

CENTRO DE EXECELÊNCIA EM TURISMO

PÓS-GRADUAÇÃO EM QUALIDADE DE ALIMENTOS

\title{
AVALIAÇÃO DA SATISFAÇÃO DA CLIENTELA EM RESTAURANTES DO TIPO SELF-SERVICE DE BRASÍLIA
}

Aluna: Andreza Paulo Nobre

\begin{abstract}
Monografia apresentada ao Centro de
Excelência em Turismo da

Universidade de Brasília como requisito parcial para obtenção do certificado de Especialista em Qualidade de Alimentos.
\end{abstract}

Orientação: MSC. Raquel Botelho

Brasília, DF, abril, 2004. 
UNIVERSIDADE DE BRASÍLIA

CENTRO DE EXECELÊNCIA EM TURISMO

PÓS-GRADUAÇÃO EM QUALIDADE DE ALIMENTOS

AVALIAÇÃO DA SATISFAÇÃO DA CLIENTELA EM RESTAURANTES DO TIPO SELF-SERVICE DE BRASÍLIA

Aluna Andreza Paulo Nobre

Excluído:

Banca Examinadora

MSC. Raquel Botelho

Orientadora

Dra. Wilma Coelho Araújo

Membro da Banca

Brasília - DF

Abril - 2004 
Ficha Catalográfica

Nobre, Andreza Paulo

Avaliação da satisfação da clientela em restaurantes do tipo self-service de Brasília. 37 páginas.

Monografia do curso Especialização em Qualidade de Alimentos - Universidade de Brasília. Centro de Excelência em Turismo. Brasília, 2004.

Área de concentração - Nutrição

Orientadora - Raquel Botelho

1. Nutrição 2. Serviço de Alimentação 3. Self-service

Excluído: ๆ

I

I 


\section{DEDICATÓRIA}

Aos meus pais e a minhas irmãs e ao Paulo Henrique, pelo incentivo e apoio durante os primeiros passos da minha jornada. 


\section{AGRADECIMENTOS}

1

Agradeço a Deus pela força, inspiração e saúde.

A Raquel, minha orientadora, pela paciência, compreensão e incentivo durante a elaboração deste trabalho.

As Empresas prestadoras de serviços de alimentação, que permitiram a coleta de dados para elaboração deste trabalho.

Excluído:

ใ

I 


\section{RESUMO}

O presente trabalho teve o intuito de avaliar o nível de satisfação da clientela quanto o serviço de alimentação oferecido em restaurantes do tipo self-service de Brasília, incluindo o atendimento dos funcionários; a qualidade dos utensílios e equipamentos de uso da clientela; a higiene do restaurante dos utensílios e equipamentos, de acordo com a característica de cada empresa.

A amostra foi constituída de 105 clientes, divididos entre os dois restaurantes: 60 clientes representam o restaurante 1 e 45 representam o restaurante 2. Estes clientes foram selecionados aleatoriamente, entre homens e mulheres com variado grau de escolaridade. O conteúdo do questionário apresentava perguntas referentes: à freqüência da utilização do serviço, o serviço do atendente, a higiene do ambiente, a conservação e a higiene dos equipamentos e utensílios, entre outros aspectos . As perguntas eram objetivas e aplicou-se o teste da escala hedônica, para avaliar o nível de satisfação da clientela .

Os resultados indicam que o nível de satisfação quanto ao serviço dos atendentes nos restaurantes foi o que apresentou maior impacto quanto à insatisfação dos consumidores, variando entre $40 \%$ e $22,2 \%$.

Palavra Chave: serviço de alimentação, self-service, satisfação da clientela, qualidade, restaurante. 


\section{SUMMARY}

The present work had the intention of evaluating the level of satisfaction of the clientele as the feeding service offered in restaurants of the type self-service of Brasília, including the employees' attendance; the quality of the utensils and equipments of use of the clientele; the hygiene of the restaurant of the utensils and equipments, in agreement with the characteristic of each company.

The sample was constituted of 105 customers, divided among the two restaurants: 60 customers represent the restaurant 1 and 45 they represent the restaurant 2 . These customers aleatoriamente were selected, among men and women with varied education degree. The content of the questionnaire presented referring questions: to the frequency of the use of the service, the service of the atendente, the hygiene of the atmosphere, the conservation and the hygiene of the equipments and utensils, among other aspects. The questions were objective and the test of the scale hedônica was applied, to evaluate the level of satisfaction of the clientele.

The results indicate that the satisfaction level with relationship to the service of the atendentes in the restaurants was what it presented larger impact with relationship to the consumers' dissatisfaction, varying between $40 \%$ and $22,2 \%$.

Key word: feeding service, self-service, satisfaction of the clientele, quality, restaurant. 
SUMÁRIO

Introdução

Revisão Bibliográfica

Objetivo geral

Objetivos Específicos

Metodologia

22

Métodos

Materiais

Resultados e Discussão

Conclusão

Referência Bibliográfica

Anexo

Glossário 
LISTA DE FIGURAS

Figura 01 - Nível de satisfação quanto ao serviço dos atendentes dos restaurantes 1 e 2

Figura 02 - Nível de satisfação em relação aos utensílios e acessórios utilizados nos restaurantes 1 e 2 


\section{LISTA DE TABELAS}

Tabela 01 - Freqüência de utilização do restaurante self-service

restaurante 1 e 2

Tabela 02 - Nível de satisfação quanto à manutenção das

instalações restaurante 1 e 2 
LISTA DE ABREVIATURAS E SÍMBOLOS

UAN - Unidade de Alimentação e Nutrição.

A\& B - Alimentos \& Bebidas 
INTRODUÇÃO

Nas últimas décadas, a rápida urbanização da população brasileira e a sua concentração nas grandes metrópoles vem revolucionando a alimentação do brasileiro. A comida fora de casa, as marmitas, o sanduíches, a influência dos imigrantes e as comidas rápidas passam a dominar a alimentação no Brasil . Essa mudança de comportamento trouxe a expansão do mercado de alimentos, que atinge setores da agricultura, indústria e comércio. Cerca de 8,8 milhões de refeições são servidas diariamente no mercado de refeições coletivas (ABERC, 1999), sem considerar os fast food, lanchonetes, bares e ambulantes (tipo de serviço que vem crescendo nos grandes centros) (BOULOS, 1999) .

Alguns fatores têm modificado o ambiente social onde se consome o alimento. $\mathrm{O}$ advento da modernidade trouxe muitas mudanças no cotidiano das pessoas. Atualmente são raras as famílias que desfrutam do prazer de fazer as refeições em casa (GARCIA, 1993). A alternativa é procurar lanchonetes, restaurantes e bares para efetuar a segunda grande refeição do dia, o almoço (ABREU, 2003).

Esta nova experiência contrasta com a forma de alimentação tradicional, retratando um processo global de homogeneização em que as pessoas formam filas, lêem o cardápio, fazem o pedido e comem em tempo recorde, mas dentro do contexto de um restaurante (WARDE, 1997). As tendências da alimentação são reflexos dessas mudanças, levando as pessoas a recorrer aos fast food em busca de rapidez e facilidade (GARCIA, 1995).

A modernidade impôs seu ritmo aos costumes, as refeições passam a ser realizadas fora de casa. $\mathrm{O}$ ato de comer se desloca, realiza-se um movimento de aceleração da vida (GIDDENS, 1991). Os drive-in realizaram a adequação da refeição ao ritmo dos automóveis, acelerado pelo fast food, através da aplicação do modelo Taylorista das fábricas à produção de sanduíches e no atendimento ao cliente (CORR, 1996).

O conceito fast food tem mudado significativamente. Mais recentemente, tem se desenvolvido num espectro de comida preparada, em que se oferece de tudo, desde sanduíches e saladas, até pizzas, pastéis, comidas étnicas, donuts e lojas de conveniência. Inclui, ainda, restaurantes tipo self-service e "por quilo " , cafés, produtos de padaria e serviço de entrega domiciliar (ABREU, 2003).

As mudanças ocorridas no segmento de restaurantes comerciais mostram uma nova fase desse ramo de atividade. Dentro desse novo cenário, surgiu o conhecido restaurante "por quilo", um fenômeno nacional com custo atrativo, mas que, nem sempre, atende às 
necessidades nutricionais. O consultor Magnée citado por MARICATO (1996), afirma que mais de 50\% sejam "por quilo". Esse tipo de restaurante passa a ser mais interessante que o self-service simples, pois o cliente escolhe apenas aquilo que pretende consumir, ciente de que os restos (alimentos servidos e não consumidos) sairão de seu próprio orçamento. Por outro lado, a possibilidade de escolher por peso, faz com que se gaste na medida da disposição financeira (MARICATO, 1996) (ABREU, 2003).

Assim, a comida "por quilo" deixou de ser um modismo e se tornou hábito de consumo. O cliente do restaurante "por quilo" tem a seguinte opinião: "gosto porque escolho o que vou comer", mas na realidade, ele escolhe entre as opções que o restaurante lhe oferece (MAGNÉE, 1996) (ABREU, 2003).

As exigências cada vez maiores do consumidor, têm gerado competição entre as indústrias de alimentação que precisam obter produtos de melhor qualidade para satisfazer as demandas de mercado. Um dos principais aspectos do desempenho de uma empresa é a qualidade de seus produtos e serviços. É ela quem garante ao consumidor o atendimento das necessidades ou requisitos de segurança, durabilidade e desempenho dos produtos. (MOREIRA, 1995, ABNT, ISSO 9000) (FERREIRA, 2002).

Com a globalização, o controle da qualidade adquiriu amplitude e a produção de serviços passou a atender normas para garantir a eficiência do sistema e, por questões de mercado, a certificação da série de Normas Internacionais (ISO 9000 a 9004) na empresa tornou-se uma obrigatoriedade. Na aplicação da ISSO 9002 em sistemas de alimentação coletiva, a avaliação do ciclo de qualidade ocorre desde o marketing até a utilização do produto alimentício pelo cliente. As etapas, que compreendem desde o controle de fornecedor, aquisição de gêneros alimentícios, recepção de produtos, produção, armazenamento, distribuição e treinamento de pessoal requerem a elaboração de manual de qualidade onde são postos os procedimentos para garantir o controle da qualidade do serviço, atendendo assim, a expectativa do cliente (FERREIRA, 2002).

Considerando que qualidade é aquilo que satisfaz o cliente, controle da qualidade e a manutenção do produto dentro dos níveis e tolerâncias aceitáveis para o consumidor ou comprador. Para obter alimentos de boa qualidade, é necessário controlar todos os aspectos relacionados ao sistema que podem ser distribuídos em responsabilidades perante a direção da empresa, a equipe de produção e os consumidores. Estas responsabilidades auxiliam no sentido de manter o nível da qualidade dos alimentos, baixar e/ou minimizar custos, reduzir despesas e queixas, defeituosos, usar métodos de correção para as falhas do 
processo, assegurar ao cliente alimentos de boa qualidade e alto valor nutritivo (MOREIRA, 1995, ABNT 9000) (FERREIRA, 2002).

Englobando esta visão de Qualidade, no setor de produção de refeições, entende-se que a Qualidade Total em uma Unidade de Alimentação e Nutrição (UAN) pode significar o fornecimento de refeições balanceadas e microbiologicamente adequadas, de acordo com as necessidades nutricionais do cliente externo e interno e o oferecimento de refeições com o menor custo, a preços considerados razoáveis para os clientes (FERREIRA, 2002).

Apresentar, métodos para melhoria da unidade de alimentação oferecido nos restaurantes self-service, com o intuito de reduzir o número de reclamações da clientela, conduz a satisfação da clientela. Uma vez que o cliente mais conscientizado de seus direitos e mais amparado pelas leis, apresenta um nível de exigência muito maior (FERREIRA, 2002). 


\section{REVISÃO BIBLIOGRÁFICA}

A alimentação constitui uma das atividades humanas mais importantes, não só por razões biológicas evidentes, mas também por envolver aspectos sociais, psicológicos e econômicos fundamentais na dinâmica da evolução das sociedades. Os recursos envolvidos em alimentação, em termos de mercado, são consideráveis, perfazendo um montante bastante superior a setores como automobilístico, eletrônico ou de armamento (PROENÇA,1997).

A necessidade do homem de alimentar-se determina uma busca por alimentos que tragam a satisfação. Muito mais que a satisfação biológica, a psicológica os incita a fazer das refeições, rituais onde proporciona a reunião de pessoas de mesmo interesse.

O hábito de realizar refeições fora de casa está se tornando cada vez mais rotineiro, e uma das formas de atender esta demanda são os restaurantes self-service a quilo. Esse hábito é decorrente da vários fatores: como o aumento do trabalho feminino, a distância entre o domicílio e o lugar de trabalho, as dificuldades de transportes, a adoção da jornada contínua com somente uma hora de interrupção do trabalho para o almoço, a falta de tempo para preparar a própria refeição em casa, a praticidade e a variedade de preparações oferecidas (STORCK , 2003).

Segundo dados da ABIA - Associação Brasileira da Indústria de Alimentos, em média, o brasileiro faz uma a cada quatro refeições fora de casa 25\%, e nos Estados Unidos, 46\%. Assim, o número de restaurantes aumentou de 400.000 em 1991 para 756.000 em 1998, sendo que existem 1.036.180 pontos de venda de refeições fora do lar, com 41 milhões de refeições servidas por dia. Estima-se que somente na cidade de São Paulo estejam localizados 5.000 restaurantes (MAGNÉE, 1996).

Um dos fatores que agilizou o crescimento de refeições fora do lar e de consumo de alimentos de rápido preparo foi a entrada da mulher no mercado de trabalho, que, em 1971, correspondia a apenas $23 \%$ da população economicamente ativa e, em 2000, a 51\%. Com isso, o tempo disponível para o preparo das refeições passou de 2 horas para 15 minutos, o que reestruturou a forma da família se alimentar (ABIA 2002).

Uma das formas de atendimento a esta demanda é a entrada restaurantes selfservice, a quilo, nos quais o consumidor tem acesso à uma refeição variada e de baixo custo, podendo escolher os componentes de seu prato, de acordo com o gosto pessoal (STORCK, 2003). 
Segundo dados de 2002 da ABIA, desde a implantação do plano real até 2001, houve um crescimento de 19,7\% dos setores de food service e de 16,5\% de alimentação fora do lar. O número de restaurantes comerciais no Brasil duplicou na última década e movimentou R 5,2 bilhões de reais em 2001.

Avaliando o crescente mercado de refeições coletivas, as empresas tendem a melhorar o serviço oferecido, já que a concorrência cada dia é maior. Com esse intuito de permanecer crescente no mercado, a empresa deve trabalhar com uma visão de qualidade total da sua unidade de alimentação oferecido. Tendo em vista a necessidade da manutenção do serviço de alimentação com qualidade, para redução total do número de reclamações existentes.

Os restaurantes desempenham um importante papel na sociedade. Comer fora, num restaurante, satisfaz a uma necessidade sociológica fundamental. As pessoas não necessitam somente da suas características culturais e sociais. Por essas razões, houve uma demanda maior do crescimento da chamada refeição por quilo. Fazendo um parêntese, vale citar que os restaurantes serviços com esse perfil, invenção nacional, estão fazendo tanto sucesso que os EUA e a Europa já copiaram o modelo. A forma do quilo deriva do fastfood, categoria de restaurante nascido nos EUA no ano de 1950. Logo após, o termo passou a indicar comida rápida, semi-pronta ou pronta, que oferece diversas opções (SILVA, 2001). O "quilo" faz parte da última geração da família do fast food, parecido com o self-service, que em vez do preço fixo, cobra-se por quilo. Ele mistura receitas de gastronomia sofisticada com dicas de cozinha caseira. Neles os clientes encontram desde pratos mais finos ao trivial arroz com feijão. (SILVA, 2001).

Há “quilos” para os diversos gostos e bolsos. Alguns possuem supervisão e controle de qualidade com nutricionistas, uma necessidade cada vez mais presente. Essa refeição passou a ser um hábito de consumo incorporado diretamente ao perfil atual do consumidor (SILVA, 2001).

Nos restaurantes self-service que atendem a um público mais exigente a associação de todos esses fatores, incluindo-se a dietética, passa a ser uma necessidade na prestação de um serviço de qualidade (GARCIA, 2002).

Conforme a Lei Federal 8234/91, a qual regulamenta a profissão de Nutricionista, observa-se no seu "art. $3^{\circ}$ : - São atividades do nutricionista: II - planejamento, organização, direção, supervisão e avaliação da Unidade de Alimentação e Nutrição .

O êxito no funcionamento das Unidades de Alimentação e Nutrição (UAN) está na dependência da definição clara de seus objetivos, de sua estrutura administrativa, de suas 
instalações físicas e recursos humanos e, sobretudo, da normatização de todas as operações desenvolvidas, que devem ser respaldadas nos cincos elementos do processo administrativo básico, previsão, organização, comando, coordenação e controle (TEXEIRA, 2000).

O objetivo de uma UAN é o fornecimento de uma refeição equilibrada nutricionalmente, apresentando bom nível de sanidade, e que seja adequada ao cliente. Esta adequação deve ocorrer no sentido de manutenção e/ou recuperação da saúde do cliente, visando auxiliar no desenvolvimento de hábitos saudáveis, a educação alimentar (PROENÇA, 1997).

O papel do nutricionista no mercado atual, não é simplesmente trabalhar na produção do restaurante comercial, coordenando apenas os seus colaboradores, mas trabalhando de forma contínua e integrada com todo o processo de gestão e gerência de ALIMENTOS \& BEBIDAS do estabelecimento. Essa integração das gestões que contribuem para melhoria contínua da qualidade do estabelecimento, de forma a trabalhar pela satisfação da sua clientela.

Com os novos sistemas de atendimento nos Restaurantes de Coletividades (selfservice/ multi - produto/ livre - escolha), a atuação do nutricionista também muda, tornando-se muito mais orientador/ educar e, portanto, mais próximo de seu cliente (BERNARDO, 1999). Portanto o "fazer acontecer ", na prática é com certeza o maior desafio da nutrição e do nutricionista, com intuito único da melhoria contínua da qualidade, através de atualizações, treinamento e atualização dos funcionários, e inovações no que rege a alimentação.

A U.A.N. tem a função de fornecer alimentação balanceada e a mais completa possível ao seu público alvo. Respeitando as recomendações dietéticas padronizadas para grupos populacionais de acordo com os aspectos da população assistida (TEXEIRA, 2000).

Além dos aspectos ligados a refeição, uma UAN objetiva a satisfação da clientela no que diz respeito ao serviço oferecido. Onde esse serviço engloba desde o ambiente físico, incluindo tipo, conveniência e condições de higiene das instalações, equipamentos e utensílios disponíveis, até o contato pessoal entre operadores da UAN e comensais, nos mais diversos momentos.

A nível de Empresa, o oferecimento de uma alimentação balanceada, de conformidade com as recomendações nutricionais, é a condição “ sine Qua non” para o alcance de objetivos altamente desejáveis, dentre os quais: aumento da produtividade do produto, redução de acidente de trabalho, diminuição do absenteísmo e da rotatividade da 
mão de obra. De modo mais abrangente, pode-se afirmar que o oferecimento de uma alimentação cientificamente equilibrada constitui um instrumento de maior interação funcionário/empresa (TEXEIRA, 2000).

Hoje um cliente quer saber o que está comendo, seu modo de preparo, sua composição, valor calórico, apresentação e principalmente a valorização do sabor e da qualidade dos alimentos.

Em função dessa exigência do cliente, o nutricionista deve começar a se adaptar a essa nova realidade, voltando sua administração para a busca de resultados contínuos que atendam a essa nova necessidade do restaurante. E não apenas que as refeições sejam nutricionalmente adequadas e que proporcionam uma satisfação da sua clientela.

$\mathrm{Na}$ atual economia, promover excelentes serviços aos clientes pode ser uma diferença critica no sucesso de uma empresa. $\mathrm{O}$ atendimento a clientes não significa apenas fazer produtos de alta qualidade, embora esta seja uma parte importante desse atendimento. As pessoas não toleram produtos de má qualidade, elas os devolvem e passam a comprar em outro lugar. É preciso vender produtos de qualidade para cativar clientes. Portanto, é preciso oferecer excelência aos clientes para mantê-los.

O sucesso das operações de um restaurante depende de fatores, desde a filosofia de administração até os controles de custos, passando por tudo o que existe de intermediário entre estes itens. Fazer que um empreendimento destes tenha sucesso não é tarefa das mais fáceis (WALKER, 2002).

Todo o processo de produção, comercialização e industrialização de alimentos, deve estar vinculado e voltado a oferecer alimentos que realmente preencham a função de nutrição, assegurando a inocuidade de alimentos (NASCIMENTO,2000).

Não apenas o comércio de alimentos está necessitando adequar-se as exigências e necessidade do cliente, mas toda a indústria e parte de vendas. Esta necessidade que buscará o diferencial entre os concorrentes. O cliente esta cada vez mais, buscando produtos e serviços de qualidade, que atendam a sua necessidade e, que tenham um baixo custo de preferência (MENZOMO, 2002).

Qualidade é um termo que tem conceitos variados e dinâmicos, mas fundamentalmente ele indica o nível de excelência do que é produzido (produtos e serviços). A qualidade não é um programa com início e fim determinados, mas um processo que, tem início, não conhece o fim. Isto devido ao fato de a qualidade ser um conceito dinâmico, que supõe e envolve uma melhoria continuada, levando a organização a buscar incessantemente novos níveis de performance (MENZOMO, 2002). 
A melhoria continuada da qualidade tornou-se o assunto mais debatido desta década e a pauta obrigatória de todas as reuniões administrativas, tanto na área industrial, quanto nas organizações prestadoras de serviços. Esse tema continua a desafiar a criatividade dos administradores conscientes de sua responsabilidade e desejos do desenvolvimento futuro de suas organizações (MENZONO, 2002).

A qualidade passou a ser símbolo e condição para a sobrevivência e a própria legitimidade social das organizações. A qualidade é, e sempre será, a marca das empresas de sucesso, como o fracasso será a sina dos que nela não acreditam. Através da qualidade, há uma nova relação de parceria entre os fornecedores e cliente, priorizando a pessoa, na figura do cliente, como fundamento e razão de ser de todo o esforço empresarial. A qualidade mostrou que o cliente não é uma pessoa sob domínio, mas um colaborador e parceiro na obtenção dos objetivos maiores da organização. A qualidade veio mostrar que toda a organização deve definir sua própria identidade, estabelecer sua missão, formular os valores que caracterizam e os princípios que orientam em suas atividades (MENZONO, 2002).

A própria administração, muitas vezes, despreparada e ineficiente, não se dá conta da importância de um serviço de qualidade como forma e caminho de integração da empresa com a comunidade consumidora. Existem, por outro lado, muitas empresas de serviços que estão passando pôr uma evolução e progresso incríveis, justamente pôr que optaram pela qualidade, ou seja, pelo respeito ao consumidor. A tendência é de ter cada dia mais serviços, mas eles não sobreviverão se não tiverem qualidade (MENZONO, 2002).

Qualidade de um serviço é o resultado de um esforço de operações para descobrir exatamente o que o cliente quer. Uma vez que essas necessidades e desejos sejam conhecidos, os procedimentos são implementados para atender a essas solicitações de forma efetiva e constante. Quando uma operação satisfaz as expectativas do cliente, está proporcionando a qualidade de serviço. Não se pode negar que os funcionários das unidades de alimentação contribuem também para o sucesso ou fracasso de uma operação de um restaurante (DAVIES,1999).

Proporcionar qualidade como o cliente a define significa compreender plenamente ambas as dimensões da qualidade: qualidade do produto e qualidade do serviço. As poderosas técnicas introduzidas por Deming e Juran lidam, sobre tudo, com a qualidade do produto; “O que você obtém”. A qualidade do produto costuma ser quantificável. Porém, para inspirar os empregados a medirem seus esforços e resultados em relação às necessidades e expectativas dos clientes, é preciso comunicar tais necessidades e 
expectativas e mostrar que se acredita sinceramente em que elas podem e devem ser satisfeitas. As necessidades dos clientes precisam ser ensinadas, enfatizadas e reveladas constantemente através do próprio treinamento (WHITELEY, 1992).

A busca da qualidade vem tendo um destaque muito grande em nível mundial, devido a uma série de fatores que vem movimentando as organizações, tais como: o aumento da competitividade em nível mundial; o aumento dos custos de produção; o aumento do nível de exigência por parte do consumidor e o correspondente aumento do número de processos jurídicos contra as empresas (produtos e serviços); e o surgimento das novas leis de proteção ao consumidor. A qualidade visa à satisfação dos clientes, busca identificar, superar e extrapolar as expectativas e necessidades destes (MENZONO, 2002).

As reclamações dos clientes são necessárias para o estabelecimento, pois, é o meio pelo qual os gerentes de A\&B, possam desenvolver sistemas de feedback para saber como os clientes estão reagindo ao serviço, para que cada problema identificado possa ser rápida e totalmente solucionado (DAVIES,1999).

Cliente satisfeito é aquele que percebe que o atendimento de necessidades pela organização é pelo menos igual àquele que se esperava. 


\section{OBJETIVO GERAL}

Avaliar a satisfação da clientela quanto ao serviço de alimentação oferecido em dois Restaurantes do tipo Self-Service (auto-serviço) .

\section{OBJETIVOS ESPECÍFICOS}

- Avaliar o nível de satisfação da clientela dos Restaurantes Self-Service, quanto ao serviço oferecido pelos atendentes.

- Avaliar o nível de satisfação da clientela dos Restaurantes Self-Service, quanto a higiene do ambiente.

- Avaliar o nível de satisfação da clientela dos Restaurantes Self-Service da , quanto a conservação e higiene dos equipamentos e utensílios. 


\section{METODOLOGIA}

O trabalho foi desenvolvido entre novembro de 2003 e fevereiro de 2004. Teve como objeto de estudo dois restaurantes do tipo self-service "por quilo" de Brasília, escolhidos por conveniência para verificar a satisfação da clientela.

O estudo de caso é do tipo estruturado participante. Foi desenvolvido com dois restaurantes, no primeiro, a amostra representou $24 \%$ da clientela freqüentadora e no segundo a amostra representou 20 \% do total da média diária de sua clientela.

Inicialmente após a elaboração do questionário (anexo 1), foi aplicado um teste piloto com 30 colaboradores para avaliar o grau dificuldade na interpretação das perguntas elaboradas, o grau de dificuldade para os colaboradores independentemente do seu grau de instrução e o tempo para respondê-lo.

\section{MÉTODOS}

O conteúdo do questionário apresentava perguntas referentes: à freqüência da utilização do serviço, o serviço do atendente, a higiene do ambiente, a conservação e a higiene dos equipamentos e utensílios, entre outros aspectos . As perguntas eram objetivas e aplicou-se o teste da escala hedônica, que se refere ao estado psicológico consciente, agradável e desagradável e se aplica para análise de preferência e aceitabilidade, com provadores não treinados. As respostas afetivas são medidas por escala de pontos; o provador expressa sua aceitação pelo produto seguindo uma escala previamente estabelecida (7 pontos) que varia gradativamente entre os atributos gosta e desgosta de uma amostra.

Os dados foram tratados no programa SPSS 10.0 para Windows para obter freqüência, média e mediana dos resultados. 


\section{MATERIAIS}

A escolha dos clientes nos dois restaurantes foi aleatória, explicava-se o caráter não obrigatório, da pesquisa assim como a não vinculação com os restaurantes pesquisados.

A amostra foi constituída de 105 clientes, divididos entre os dois restaurantes: 60 clientes representam o restaurante 1 e 45 representam o restaurante 2. Estes clientes foram selecionados aleatoriamente, entre homens e mulheres com variado grau de escolaridade. No restaurante 1, o número de clientes selecionados representou $24 \%$ da sua média diária dos usuários do restaurante, enquanto no restaurante 2 o número selecionado representou 20\% da sua média diária. 


\section{RESULTADOS E DISCURSSÕES}

As tendências evolutivas do setor de alimentação coletiva no Brasil podem ser analisadas a partir de duas vertentes, o potencial latente atual devido à cobertura deficiente do mercado existente e as alterações demográficas e sócio - econômicas intervenientes no setor (PROENÇA, 1997).

O hábito de realizar as refeições fora de casa está se tornando cada vez mais comum, e uma das formas para atender esta demanda são os restaurantes self-service à quilo. Mas esse hábito, é decorrente de alguns fatores: como o aumento do trabalho feminino, a distância entre domicílio e o lugar de trabalho, as dificuldades de transporte, a adoção da jornada contínua com somente uma hora de interrupção do trabalho para o almoço, a falta de tempo para preparar a própria refeição em casa, a praticidade e a variedade de preparações oferecida (STORCK, 2003).

O consumidor em alimentação coletiva, denominado cliente, pode ser considerado cativo quando se encontra nos subsetores de saúde e assistência social, prisões, forças armadas, ensino para crianças, bem como empresas com localização isolada. Nestes casos, por circunstâncias ligadas à atividade (profissional ou escolar) ou a estado (doença, velhice, encarceramento), não lhe é dada opção sobre o local das refeições. Já o consumidor da alimentação no trabalho e do ensino para adolescentes e adultos é analisado como relativamente cativo, pois pode, muitas vezes, optar sobre a utilização da unidade de alimentação coletiva disponível (PROENÇA, 1997).

Rodrigues (1991) enfatiza que a satisfação do cliente com a refeição é, normalmente, influenciada por fatores sócio - econômicos, grau de satisfação do indivíduo com a coletividade em questão, necessidades e expectativas sociais representadas pela individualidade, status, gostos e preferências (PROENÇA, 1997).

Rastoin et al (1991) destaca que alguns são aspectos analisados como as grandes tendências de comportamento dos clientes nas sociedades de consumo dos países industrializados, a autonomia, a convivência, a desestruturação das refeições, o convívio, o cosmopolitismo, o refinamento, o equilíbrio alimentar, a valorização do natural e a valorização da alimentação fora de casa (PROENÇA, 1997).

A autonomia representa a aspiração do cliente à diversidade tanto de produtos como de serviços e local da alimentação, numa tentativa de rompimento com as tradições. Este aspecto está intimamente ligado à conveniência, que demonstra o desejo de poder contar com os progressos técnicos disponíveis para simplificar o momento da refeição. 
A tabela 1 demonstra a freqüência de utilização do restaurante self-service. Verifica-se que no restaurante 1: 5\% dos entrevistados utilizam o restaurante 2 vezes por semana; 13,3\%, 3 vezes por_semana; 36,7\%, 4 vezes por semana e 45\%, 5 vezes por semana. Os dados apresentam a mesma tendência para o restaurante 2: 6,7\% utilizam restaurantes do tipo self-service 2 vezes por semana; 8,9\%, 3 vezes por semana; 44,4\%, 4 vezes por semana e 40\%, 5 vezes por semana. Dos resultados obtidos, observa-se que a maioria dos entrevistados utiliza este serviço mais de 4 vezes por semana. $\mathrm{O}$ aumento no número de refeições feitas fora de casa está relacionado com a tendência crescente de inúmeros fatores que podem ser agrupados em três categorias: transformação dos modos de vida (novos comportamentos alimentares, progressão do poder de compra, desenvolvimento do lazer e modificação da estrutura familiar), desenvolvimento da atividade (trabalho feminino, alteração de horários de trabalho e estudo, deslocamentos profissionais, implantação e implementação dos tíquetes-restaurante) e transformação da ocupação espacial transformação das cidades, desertificação rural (PROENÇA, 1997).

TABELA 1 - FREQUÊNCIA DE UTIZAÇÃO DO RESTAURANTE SELF-SERVICE (RESTAURANTE 1 E 2)

\begin{tabular}{|l|c|c|c|c|}
\hline & \multicolumn{2}{|c|}{ RESTAURANTE 1 } & \multicolumn{2}{c|}{ RESTAURANTE 2 } \\
\hline & Freqüência (N) & Percentual (\%) & Freqüência (N) & Percentual (\%) \\
\hline 2 vezes na semana & 3 & 5,0 & 3 & 6,7 \\
\hline 3 vezes na semana & 8 & 13,3 & 4 & 8,9 \\
\hline 4 vezes na semana & 22 & 36,7 & 20 & 44,4 \\
\hline 5 vezes na semana & 27 & 45,0 & 18 & 40,0 \\
\hline Total & 60 & 100,0 & 45 & 100,0 \\
\hline
\end{tabular}

Os novos comportamentos alimentares observados ressaltam que as pessoas estão dando menos importância às refeições tradicionais e concomitantemente, aumentando as preocupações com relação à nutrição e a procura por refeições equilibradas e saudáveis, embora diminua o tempo disponível para ocupar-se com a alimentação. A modificação da estrutura familiar é também colocada como um fator importante, na medida em que é crescente a tendência das pessoas morarem sozinhos, como, jovens estudantes, solteiros, divorciados e idosos. Considera-se, ainda, a progressão global do poder de compra 
observada em vários países desenvolvidos e a valorização do tempo livre com o desenvolvimento de estruturas de lazer (PROENÇA, 1997).

A progressão do trabalho feminino, observada praticamente em todos os países da Europa e nos Estados Unidos, tem uma repercussão direta no aumento das refeições fora de casa, principalmente nos setores de ensino e trabalho. Ocorreu a diminuição da disponibilidade feminina para a confecção de refeições para família e também o aumento de renda familiar, que possibilita o acesso a novos padrões de consumo. Na França, o coeficiente de despesa com a alimentação fora de casa dobra em famílias cuja mulher está incorporada ao mercado de trabalho (Manon, 1993; PROENÇA, 1997).

A alteração dos horários de estudo e de trabalho e a generalização da jornada contínua, bem como o aumento dos deslocamento profissionais são citadas devido à dificuldade de conciliar o tempo entre a atividade principal e a alimentação. Os tíquetes alimentação permitem ao trabalhador o acesso às refeições a preço subsidiado em serviços de alimentação comercial e coletiva (PROENÇA, 1997).

Com relação à transformação da ocupação do espaço, observa-se a tendência de aglomeração populacional em espaços urbanos com a conseqüente diminuição em espaços rurais. O crescimento das cidades e a organização espacial das mesmas, com a diferenciação de locais para habitação e atividades produtivas, ocasionam o aumento da distância entre a casa e trabalho. Pode tornar-se, assim, muito difícil a locomoção para realizar refeições em casa, por questões de tempo e dinheiro (PROENÇA, 1997)

Com relação ao nível de satisfação, observa-se que em relação ao restaurante 1 , Excluído: १ 1,7\%, dos entrevistados gostam moderadamente dos serviços dos atendentes; 32\% gostam ligeiramente; 40\% não gostam / nem desgostam; 25\% desgostam ligeiramente; 1,7\% desgostam moderadamente. Para o restaurante 2, 2,2 \% dos clientes gostam moderadamente do serviço; 31,1\% gostam ligeiramente; 22,2\% não gostam / nem desgostam; 26,7\% desgostam ligeiramente; 17,8\% desgostam moderadamente como mostra a figura 1. 


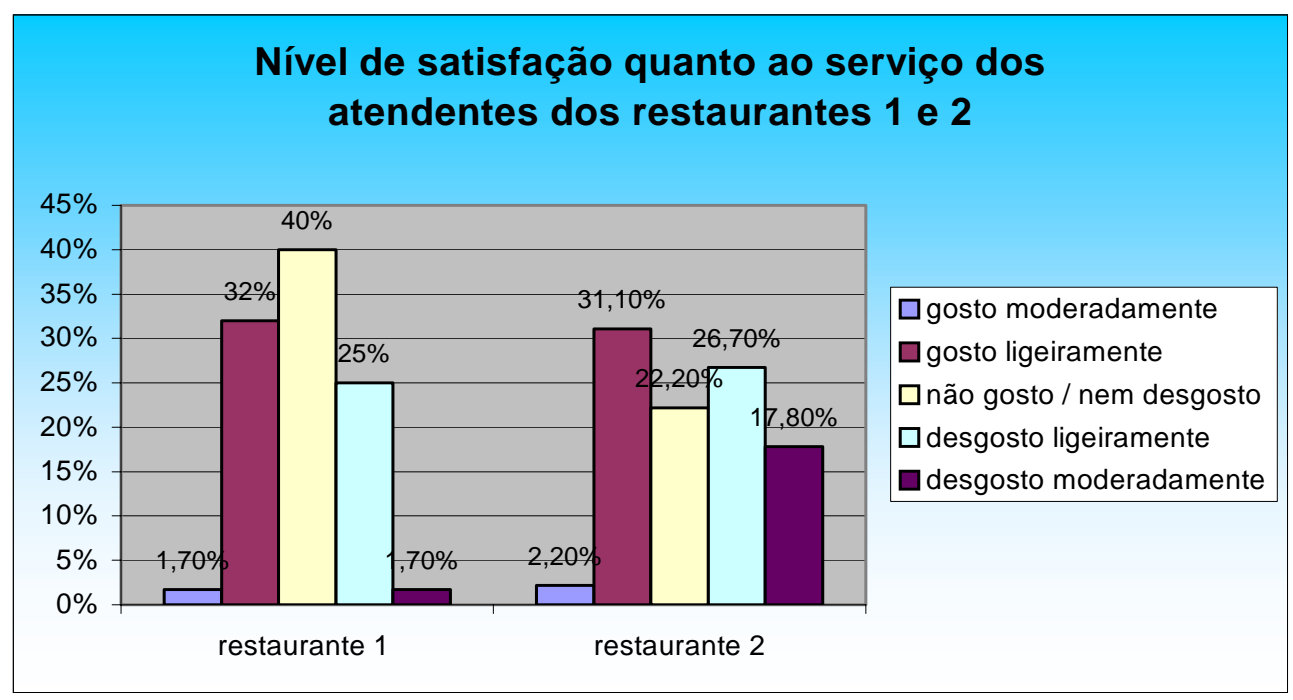

FIGURA 1 - NIVEL DE SATISFAÇÃO QUANTO AO SERVIÇO DOS ATENDENTES DOS RESTAURANTES 1 E 2

Sobre as características do restaurante 1 , verifica-se que o restaurante 1 possui uma clientela mais exigente, constituída em sua maioria por jovens, , que buscam uma melhoria contínua do serviço oferecido pelos atendentes; o segundo restaurante possui uma clientela mais variada. De acordo com a média de idade apresentada pelos entrevistados nos dois restaurantes.

Na unidade de alimentação do tipo self-service, os balcões frios e quentes são montados antes da abertura do restaurante; a organização dos materiais utilizados durante o almoço é feita antes do horário de funcionamento ao público. Entretanto, cabe aos atendentes organizar também as reservas para o momento oportuno da reposição das preparações, evitando a espera por parte dos clientes. Além do mais, cabe também aos atendentes o recolhimento dos pratos da mesa, de certo modo organizando-a para que o próximo consumidor possa se sentar. Este tipo de atitude não agrada dada a pressão exercida com relação à liberação da mesa, o que explica o grau de satisfação dos clientes nos restaurantes pesquisados.

Tendo uma ligação direta com freqüência média da clientela diária que é maior no primeiro restaurante e avaliando que os dois restaurantes possuem quase o mesmo espaço físico para ser ocupado com mesas para as refeições, os atendentes do restaurante 1, ficam obrigados a recolher com maior rapidez e ainda sem causar nenhum transtorno à clientela. Entretanto, devido a grande movimentação dos atendentes, parte destes clientes ficam insatisfeitos pela falta de cordialidade e hospitalidade gerada por esta situação. Já o 
restaurante 2, por sua média de clientela diária, ser menor consequentemente tem um fluxo mais tranqüilo sem tantas insatisfações quanto ao atendimento dos funcionários.

A modalidade do serviço self-service reduz consideravelmente o quadro de pessoal envolvido na distribuição e no atendimento ao cliente, pois o próprio cliente serve a sua alimentação e sua bebida, sendo que atendentes têm somente a função de recolher os pratos e talheres das mesas e repor o material utilizado.

Ainda dentro desta perspectiva, o ambiente onde se desenvolvem as relações de hospitalidade tem a mesma importância para atrair e promover a satisfação do cliente, seja ele um paciente, estudante, prisioneiro, turista ou empregado, independentemente de tratarse de indústrias de hospitalidade institucional ou aquela que visa ao lucro. Daí a importância de serem observados os aspectos, por assim dizer, indiretos que não representam o produto em si, mas que colaboram para sua avaliação, tais como a cordialidade do serviço, o conforto do ambiente, a qualidade, entre outros (DIAS, 2002).

Com relação à higiene do ambiente, verifica-se no restaurante 1 que 22,2\% responderam gostar moderadamente; 33,3\% gostam ligeiramente; 24,4\% não gostam / nem desgostam; 20\% desgostam moderadamente. Para o restaurante 2, os dados indicavam que $31,7 \%$ gostam moderadamente; $30 \%$ gostam ligeiramente; $20 \%$ não gostam / nem desgostam e 18,3\% desgostam ligeiramente.

Para aumentar o nível de satisfação dos clientes em relação à higiene do ambiente, as superfícies utilizadas para exposição de alimentos, bem como equipamentos e utensílios, devem estar bem higienizadas para não tornarem focos de contaminação e reclamações dos clientes. A higienização correta, tais como, a lavagem com água e sabão, permite reduzir os resíduos orgânicos nas superfícies. Os produtos desinfetantes, ou o calor, também promovem a redução dos microrganismos deteriorantes e patogênicos a níveis suportáveis, minimizando o metabolismo microbiano e dificultando a formação de biofilmes (SILVA JÚNIOR, 2002).

Desta forma, a qualidade de um serviço ou produto em uma U.A.N., depende, em grande parte, da higiene, inclusive os vestuários com que se apresentam os empregados. É uma medida de confiabilidade na higiene da refeição produzida, que é transmitida à clientela (TEXEIRA, 2000).

O salão de refeições é o local onde os clientes fazem suas refeições. Deve estar situado em ponto que facilite o transporte da refeição pronta, preservando o grau de higiene e propriedades organolépticas e além disso, de fácil acesso aos clientes. Cuidados especiais 
devem ser dispensados à ambientação desta área, tornando-a mais agradável possível (TEXEIRA, 2000).

A tabela 2 demonstra o nível de satisfação dos entrevistados no que diz respeito a manutenção das instalações. No restaurante 1: 10\% gostam moderadamente; $65 \%$ gostam ligeiramente; $15 \%$ não gostam / nem desgosta; $10 \%$ desgostam moderadamente. Os dados apresentam a mesma tendência para o restaurante 2: 6,7\% gostam moderadamente; 64,4\% gostam ligeiramente; 17,8\% não gostam / nem desgosta; $11,1 \%$ desgostam moderadamente.

TABELA 2 - NIVEL DE SATISFAÇÃO QUANTO À MANUTENÇÃO DAS INSTALAÇÕES RESTAURANTE 1 E 2

\begin{tabular}{|l|c|c|c|c|}
\hline & \multicolumn{2}{|c|}{ RESTAURANTE 1 } & \multicolumn{2}{c|}{ RESTAURANTE 2 } \\
\hline & $\begin{array}{c}\text { Freqüência } \\
\text { (N) }\end{array}$ & $\begin{array}{c}\text { Percentual } \\
(\mathbf{\%})\end{array}$ & $\begin{array}{c}\text { Freqüência } \\
\text { (N) }\end{array}$ & $\begin{array}{c}\text { Percentual } \\
(\mathbf{\%})\end{array}$ \\
\hline Desgosto ligeiramente & 6 & 10,0 & 3 & 6,7 \\
\hline $\begin{array}{c}\text { Não gosto / nem } \\
\text { desgosto }\end{array}$ & 9 & 15,0 & 8 & 17,8 \\
\hline Gosto ligeiramente & 39 & 65,0 & 29 & 64,4 \\
\hline Gosto moderadamente & 6 & 10,0 & 5 & 11,1 \\
\hline Total & 60 & 100,0 & 45 & 100,0 \\
\hline
\end{tabular}

.

A figura 2 revela o nível de satisfação dos entrevistados em relação aos utensílios e acessórios utilizados nos restaurantes. No restaurante 1, 40\% gostam moderadamente, 26,7\% gostam ligeiramente, $20 \%$ não gostam / nem desgostam, 13,3\% desgostam moderadamente. Já no restaurante 2, 37,8\% gostam moderadamente, 20\% gostam ligeiramente, 24,4\% não gostam / nem desgostam, 14,8\% desgostam moderadamente.

Os utensílios que são utilizados pelos restaurantes pesquisados não atendem a satisfação da suas clientela, tendo em vista que o material não é de aço inox, entortam com facilidade dificultando a alimentação com tranqüilidade.

Deve-se sempre dar preferência a utensílios de aço inox, pois são fáceis de limpar e agüentam altas temperaturas. Em ambientes onde forem usados pratos e não bandejas, estes deverão ser de cor clara, não devem estar desgastados e riscados, para facilitar a 
visualização de alguma sujidade. Jamais deixar em uso louças trincadas , amaçadas, quebrados mesmo que seja uma pontinha, pois, além de denotar falta de controle, é nestas frestinhas que se alojam restos de alimento e, junto, as bactérias (SANTOS, 1999).

O cuidado com os talheres, deve sempre existir, evite cabos de madeira, além de não serem duráveis, logo apresentam farpas e um aspecto sujo, denotando falta de higiene e ainda podem abrigar microrganismos nas frestas da madeira que vão aparecendo com o uso contínuo e a água quente (SANTOS, 1999).

Para evitar falta de controle na higienização, é importante Ter sempre o número de louças e talheres na quantidade adequada, pois é muito desagradável, para quem está na espera, a falta de louças e talheres, e quando estes geralmente chegam ao cliente com resíduos de alimentos e molhados por terem sido lavados às pressas (SANTOS, 1999).

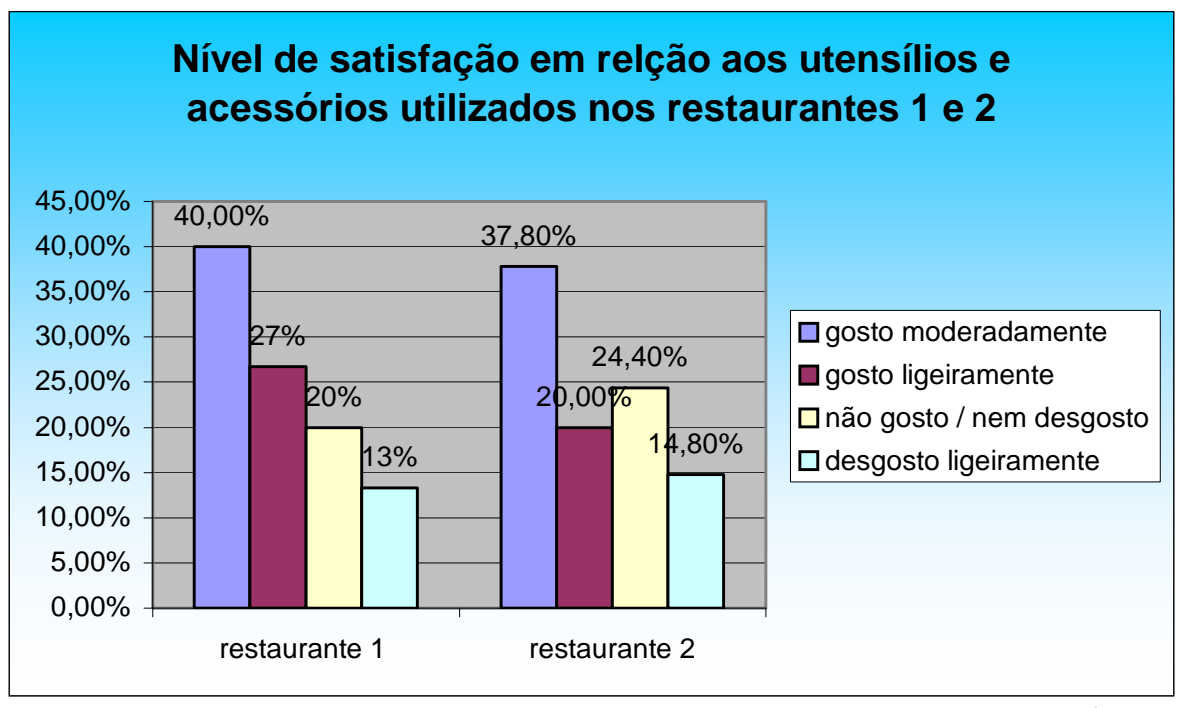

FIGURA 2 - NIVEL DE SATISFAÇÃO EM RELAÇÃO AOS UTENSÍLIOS E ACESSÓRIOS UTILIZADOS NOS RESTAURANTES 1 E 2 


\section{CONCLUSÃO}

Segundo dados de 2002 da ABIA, desde a implantação do plano real até 2001, houve um crescimento de 19,7\% dos setores de food service e de 16,5\% de alimentação fora do lar. O número de restaurantes comerciais no Brasil duplicou na última década e movimentou R\$ 5,2 bilhões de reais em 2001.

Com o crescente aumento, no setor de alimentação coletiva, o cliente, passou a visualizar com mais nitidez a necessidade de exigir e cobrar por serviço de qualidade nos estabelecimentos que oferecem alimentação. Tudo isso, faz com que o empresário tenha a condições, de visualizar quais são as necessidades primordiais dos seus clientes, para que possam ser implementadas ações que efetivamente melhorem a qualidade total do serviço oferecido.

A satisfação do cliente, torna-se necessário para sobrevivência da grande maioria dos restaurantes do mercado, tendo em vista que o cliente está cada vez mais exigente quanto o serviço que propõem a freqüentar. Avaliando o crescente mercado de refeições coletivas, as empresas tendem a melhorar o serviço oferecido, já que a concorrência cada dia é maior. Com esse intuito de permanecer crescente no mercado, a empresa deve trabalhar com uma visão de qualidade total do seu serviço de alimentação oferecido. Tendo em vista a necessidade da manutenção do serviço de alimentação com qualidade, para redução total do número de reclamações existentes.

Os restaurantes desempenham um importante papel na sociedade. Comer fora, num restaurante, satisfaz a uma necessidade sociológica fundamental. As pessoas não necessitam somente da comida que é servida, mas também da interação social que tem lugar no ambiente em que se come. Os restaurantes são um dos poucos lugares onde pode viver plenamente os cinco sentidos: o paladar, a visão, o olfato, a audição e o tato; tudo isso se torna essencial para provar da comida, dos serviços e da atmosfera de um bom restaurante (WALKER, 2002).

O cliente usuário das unidades de alimentação, busca praticidade, rapidez no atendimento, conveniências e adequação aos seus desejos, a sua situação econômica, as suas características culturais e sociais. Por essas razões, houve uma demanda maior do crescimento da chamada refeição por quilo. A forma do quilo deriva do fast-food, categoria de restaurante nascido nos EUA no ano de 1950. Logo após, o termo passou a indicar comida rápida, semi-pronta ou pronta, que oferece diversas opções (SILVA, 2001). 
Nos restaurantes self-service que atendem a um público mais exigente a associação de todos esses fatores, incluindo-se a dietética, passa a ser uma necessidade na prestação de um serviço de qualidade (GARCIA, 2002).

O êxito no funcionamento das Unidades de Alimentação e Nutrição (UAN) está na dependência da definição clara de seus objetivos, de sua estrutura administrativa, de suas instalações físicas e recursos humanos e, sobretudo, da normatização de todas as operações desenvolvidas, que devem ser respaldadas nos cincos elementos do processo administrativo básico, previsão, organização, comando, coordenação e controle (TEXEIRA, 2000).

O presente trabalho teve o intuito de avaliar o nível de insatisfação da clientela quanto o serviço de alimentação oferecido em restaurantes self-service de Brasília, avaliando todos os serviços secundários de uma Unidade de Alimentação e Nutrição, incluindo o atendimento dos funcionários; a qualidade dos utensílios e equipamentos de uso da clientela; a higiene do restaurante e dos utensílios e equipamentos, de acordo com a necessidade particular de cada um.

Pela escassez de pesquisas nesta área, vê-se a necessidade de mais pesquisas nesta área, para mostrar o quanto é necessário melhorar a qualidade dos serviços oferecidos nos restaurantes self-service de Brasília. Tendo em vista, a necessidade de oferecer mais treinamentos por parte dos gestores, já que seus funcionários devem seguir as suas orientações. Os donos dos restaurantes devem avaliar constantemente o serviço oferecido pelos funcionários, junto a sua clientela. Mas não apenas avaliar a satisfação deles, mas avaliar a qualidade total dos serviços oferecidos e a melhoria contínua dos mesmos.

O profissional nutricionista pode reverter esse quadro de insatisfação da clientela dos restaurantes do tipo self-service (à quilo). Sendo que, a clientela destes restaurantes não busca apenas uma alimentação acessível e optativa, mas também, uma alimentação saudável e equilibrada nutricionalmente e com condições higiênicas adequadas e ambientes confortáveis e agradáveis. 


\section{REFERÊNCIA BIBLIOGRÁFICA}

ABREU, E. S; TORRES, E. A . E. S. Restaurante "Por Quilo": Vale o Quanto Pesa? Uma Avaliação do Padrão Alimentar em Restaurantes de São Paulo: Revista Sociedade Brasileira Alimentos Nutrição . Jornal Brazilian Sociedade Food Nutrire. São Paulo, v.25, p. 7-21, junho, 2003.

ANGELIS, R. C. Fome Oculta. Bases Fisiológicas para Reduzir seus Riscos Através da Alimentação Saudável. São Paulo: Atheneu, p. 160-165, 2000.

ARAUJO, W. Alimentos, Nutrição, Gastronomia \& Qualidade de Vida. Revista Nutrição em Pauta, São Paulo, ano VIII, n. 43, p. 45-50, julho/ agosto, 2000.

DAVIES, C. A . Alimentos e Bebidas. Caxias do Sul: EDUCS, 1999.

SILVA JUNIOR, E. A . Manual de Controle Higiênico - Sanitário em Alimentos. São Paulo: Varela, p. 168-170, 2002.

FAUSTO, M. A. Planejamento de Dietas e da Alimentação. Rio de Janeiro: Revinter, p. 67, 2003.

FERREIRA, S. M. R. Controle da Qualidade em Sistemas de Alimentação Coletiva I. São Paulo: Varela, p. 1-9, 2002.

GARCIA,S. A .Monografia de Conclusão de Curso de Especialização de Gestão da Hospitalidade Apresentado ao Centro de Excelência em Turismo - UNB/ 2002.

MAHAN, L. K. e ESCOTT-STUMP,S. KRAUSE - Alimentos Nutrição e Dietoterapia. $9^{\mathrm{a}}$ ed. São Paulo: Rocha, p. 21-29,1998.

MAISTRO, L. C. Estudo do Índice de Resto Ingestão em Serviços de Alimentação. Revista Nutrição em Pauta, São Paulo, ano VIII, n. 45, p. 40-43, novembro/dezembro, 2000.

MENZOMO, I. B. Os Serviços de Alimentação. São Paulo: Manole, p. 83-101, 2002.

NASCIMENTO, F. C. A . Aspectos Sócio-Econômicos das Doenças Veiculadas Pelos Alimentos. Revista Nutrição em Pauta, São Paulo, ano VIII, n 40, p. 22-26; janeiro/fevereiro, 2000.

PROENÇA, R. P. C. Inovação Tecnológica na Produção de Alimentação Coletiva. Santa Catarina: Insular, p. 15-50,1997.

SILVA, S. S. O Novo Perfil do Consumidor. Revista Nutrição Saúde e Performance, São Paulo, ano 3, n 14, p. 20, dezembro, 2001. 
STORCK, C. R. et al . Monitoramento da Temperatura de Preparações Quentes e Frias em Restaurantes Self-Service, na Zona Urbana de Santa Maria. Revista Nutrição em Pauta, São Paulo, ano XI, n. 59, março/abril, 2003.

VEIROS, M. B.; PROENÇA, R. P. C. Avaliação Qualitativa das Preparações do Cardápio em uma Unidade de Alimentação e Nutrição - Método AQPC. Revista Nutrição em Pauta, São Paulo, ano XI, n. 62, p. 36-42, setembro/outubro, 2003.

TEXEIRA, M. F. G. et al . Administração Aplicada às Unidades de Alimentação e Nutrição. São Paulo: Atheneu, p. 97 - 98, 2000.

WALKER, J. R. Introdução à Hospitalidade. Barueri, S.P: Manole, p. 196,2002.

PARANAGUÁ, M. M. M. Aliando a Gestão Técnica da Qualidade em Restaurantes aos 500 Anos de uma Boa Mesa. Revista Nutrição em Pauta, São Paulo, ano VIII, n. 42, p. 32-34, maio/junho, 2000.

WHITELEY, R. C.. A Empresa Totalmente Voltada Para o Cliente: Do Planejamento à Ação. Rio de Janeiro: Campus, p. 38-39. Tradução de: The Customer Driven Company. 2003. 
ANEXO 1

PESQUISA DE OPNIÃO

SELF-SEVICE

Excluído: ๆ

\section{PESQUISA CIENTÍFICA}

\section{PREZADO CLIENTE:}

Com objetivo de avaliar o nível de satisfação dos clientes de restaurantes do tipo self-service, pedimos a gentileza de responder a pesquisa apresentada. Contando com sua colaboração para melhoraria dos serviços oferecidos, agradecemos.

RESTAURANTE 1（） $2(）$

\section{QUESTIONÁRIO}

1.Qual a sua freqüência de utilização do restaurante self-service?
( ) 1 vez na semana
( ) 2 vezes na semana
( ) 3 vezes na semana
( ) 4 vezes na semana
( ) 5 vezes na semana

2. Qual o nível de satisfação quanto ao serviço dos atendentes do restaurante?
( ) Gosto muito
( ) Desgosto ligeiramente
( ) Gosto moderadamente
( ) Desgosto moderadamente
( ) Gosto ligeiramente
( ) Desgosto muito
( ) Não gosto / nem desgosto 
3. Qual o nível de satisfação em relação à higiene do ambiente do restaurante?
( ) Gosto muito
( ) Desgosto ligeiramente
( ) Gosto moderadamente
( ) Desgosto moderadamente
( ) Gosto ligeiramente
( ) Desgosto muito
( ) Não gosto / nem desgosto

4. Qual o nível de satisfação quanto à manutenção das instalações?
( ) Gosto muito
( ) Desgosto ligeiramente
( ) Gosto moderadamente
( ) Desgosto moderadamente
( ) Gosto ligeiramente
( ) Desgosto muito
( ) Não gosto / nem desgosto

5. Qual o nível de satisfação em relação aos utensílios e acessórios utilizados? (prato, talheres, guardanapo, copos e palito)
( ) Gosto muito
( ) Desgosto ligeiramente
( ) Gosto moderadamente
( ) Desgosto moderadamente
( ) Gosto ligeiramente
( ) Desgosto muito
( ) Não gosto / nem desgosto 


\section{GLOSSÁRIO}

Alimento - "É todo o material que o organismo recebe para satisfazer suas necessidades de manutenção, crescimento, trabalho e restauração dos tecidos” (Chaves, 19978).

Alimentação - Representa o processo voluntário e consciente pelo qual o ser humano obtém produtos alimentares para o seu consumo (Proença, 1997). 